\title{
Introduction: the role of European research in understanding entrepreneurship
}

\section{Alain Fayolle, Paula Kyrö and Francisco Liñán}

This new volume in the European Research in Entrepreneurship series continues to advance knowledge in the field of entrepreneurship. Following the spirit of this book series, this volume seeks to continue identifying and making visible the common elements that underlie entrepreneurship research in Europe. In this case, the specific focus is placed on the role played by education, research, context and strategy in the process leading from the development of new entrepreneurial activity to the shaping of this activity, and to the growing of entrepreneurial projects.

The European University Network on Entrepreneurship (ESU) evolved from an initial idea to create a common space for scholars and doctoral students in which they could learn from each other. One of the central themes has been entrepreneurship education, since participants in the network have been keenly aware of the increased importance attached to developing entrepreneurship. Over more than a decade, ESU has shown that there are many commonalities in European research that can be built upon. A wide diversity has also been shown, but the existence of a constructive and collaborative approach has allowed this diversity to make an enriching contribution to the network in particular, and to entrepreneurship research in general.

In this sense, the volumes making up this series are a good example of the existence of this joint research approach in Europe. Thus, the first of these books, Entrepreneurship Research in Europe: Outcomes and Perspectives, emphasized the growing role of entrepreneurial behaviour at both individual and organizational levels in the modern era (Fayolle et al. 2005). It found that entrepreneurship needs an increased focus on behavioural theories to better understand entrepreneurial processes. At the same time, it recognized the possibilities opened by very different research methodologies.

The second, The Dynamics between Entrepreneurship, Environment 
and Education, and third, European Entrepreneurship in the Globalizing Economy, books in this series stressed the dynamic environment in which entrepreneurship research is embedded. In this sense, the former delineated a multidisciplinary landscape from which learning about the dynamic dimension of entrepreneurship could take place (Fayolle and Kyrö 2008). In turn, the latter poses some key questions about the macro and micro factors that influence European entrepreneurial development (Fayolle and Todorov 2011). They both give importance to environmental changes and how they affect the way entrepreneurship is understood and researched, how it is practised, and even how it is taught.

Within the fourth book, Entrepreneurship Research in Europe, sub-titled Evolving Concepts and Processes, a clear central issue is the adoption of a process approach to all aspects of entrepreneurship (Borch et al. 2011). The interaction of technology, environment and social practices yielding in innovative and opportunity-driven processes is a first area of analysis. The individualistic-oriented approach is now embedded into wider collective and networking processes. Thus, the multidisciplinary character of the book is evident, and results from the borrowing of ideas from several neighbouring sciences, such as sociology, psychology, management, education, organization science and philosophy.

The fifth book, Conceptual Richness and Methodological Diversity in Entrepreneurship Research, stresses the diverse research approaches in Europe, where a wide variety of qualitative research methods and combinations of these methods are often found (Fayolle et al. 2013). The book introduces an entrepreneurial element into entrepreneurship research, widening research techniques and using new methods in traditional studies, and even creating new research fields or reinventing older ones.

Throughout these books, contextual challenges have often been found to exert a relevant effect over the different aspects of entrepreneurship. In this sense, the deep economic crisis we have recently suffered has made it overwhelmingly evident that reality is even more complex than before. The challenges that have to be addressed are even greater, and the traditional public policies are now severely restrained. In particular, Europe seems to be suffering more than other advanced economies and the need to develop imaginative solutions becomes stronger than ever before. Entrepreneurship emerges, once more, as the key resource and essential instrument to contribute to economic recovery and to increase social wellbeing. The list of academics and institutions advocating the virtues of entrepreneurship is continuously growing. Nevertheless, research has found strong evidence of the complexity involved in entrepreneurial processes. In this sense, the European Research in Entrepreneurship series represents one outstanding part of this relevant research, casting light upon its complexity. 
The present book insists on the process approach. Becoming an entrepreneur is a process in which there is personal learning intertwined with environmental embeddedness in identifying opportunities. A second process relates the shaping of the venture under the influence of the context, which conditions what can be done, and by which means. Growing the venture by applying alternative strategies involves a third process, also addressed in this book. The complexity inherent in entrepreneurship is thus recognized in the approaches followed by the different chapters that form this book. The increased understanding of the entrepreneurial process in its different parts is an important step forward. This book represents the integration of multidisciplinary research, the use of diverse methodological stances and the adoption of conceptually rich approaches, three features characterizing this series and providing fruitful results so far.

This book is divided into four parts, featuring 14 chapters, following this introduction. The research presented here is the result of the work of 30 different researchers, coming from institutions in eight European countries. Part I analyses the role of education and research in helping to develop entrepreneurship. Part II is devoted to the analysis of different levels of context: cultural values, universities and teams. Different innovative strategies are considered in Part III. Finally, Part IV provides an enhanced understanding of the joint influence of context and strategy by presenting a number of case studies combining both elements.

\section{THE ROLE OF EDUCATION AND RESEARCH IN DEVELOPING ENTREPRENEURSHIP}

Part I includes four chapters focused on the development of entrepreneurship. In particular, the specific roles that education and cognitive research may play in this regard are considered. The first chapter studies an innovative doctoral programme on entrepreneurship education. The second and third ones reflect on key methodological aspects: either by building an instrument to evaluate educational programmes, or by validating an entrepreneurial intention questionnaire. Finally, the fourth chapter analyses the role of developmental networks in enhancing behavioural and cognitive competences (including entrepreneurial intention).

The chapter by Römer-Paakkanen presents a doctoral study programme that trains teachers to 'introduce' entrepreneurship into all teaching and training at their university. The doctoral study project connects theoretical studies and academic research with the participating teachers' practical work. The approach is based on the triangulation of doctoral studies (understanding of entrepreneurship theories), research (entrepreneurship 
research and doctoral dissertations) and practice (implementing theories in teaching and training of entrepreneurship). Action research methodology and constructivism as a learning and teaching paradigm are implemented in this project. This doctoral programme is helping develop more integrative, wider and more holistic entrepreneurship education programmes and curricula.

Strong complementarity with the previous chapter is shown in the contribution by Ruskovaara, Pihkala, Seikkula-Leino and Rytkölä. It aims to illustrate and model the construction of a measurement tool for entrepreneurship education where the tool itself is aimed at Finnish teachers working in basic and secondary education. This is a clear example of participatory action research, since the research context has been facilitated and provided by the researchers, and the study objects initiate, respond, and develop their activities, thereby further reforming the context. The study presents a combination of multi-method, multi-investigator, multiple data and multiple theory triangulation settings. It tries to link the theory and practice of entrepreneurship education, by using a broad and multi-layered definition of entrepreneurship education. Thus, by making these aspects explicit, the tool has the potential to work not only as a teacher's self-evaluation kit but also as a steering system for developing schools and regions on a larger scale.

Rueda, Moriano and Liñán also stress methodology in presenting the validation of an Entrepreneurial Intention Questionnaire (EIQ) over a sample of more than 3,000 Spanish university graduates. The EIQ is based on the Theory of Planned Behavior (TPB), which has been widely used to predict entrepreneurial intentions, with satisfactory results. This TPB theory offers a coherent and generally applicable theoretical framework, enabling the understanding and prediction of entrepreneurial intentions by taking into account not only personal but also social factors. In this sense, the main contribution of this EIQ is the strict adherence to Ajzen's methodological recommendations on how to construct a TPB questionnaire using composite measures of attitudes and subjective norms (Ajzen 2006). The structural equation modelling (SEM) technique is used to confirm the EIQ has a high reliability and validity to measure Spanish university graduates' entrepreneurial intentions.

In their chapter, Gruber-Muecke and Kailer empirically investigate how Junior Enterprises are related to the process of entrepreneurial competence development inherent in entrepreneurship education. They propose that this analysis is one key missing piece in the debate on the impact of entrepreneurship education. Using a developmental network perspective, the chapter proposes that competence development among Junior Enterprise members is influenced by both former and active peer 
members. The study uses empirical data from a European survey to analyse how the cognitive, functional and behaviour-related competencies of Junior Entrepreneurs are linked to their entrepreneurial intention. Overall, the developmental network perspective is proposed as an alternative to the traditional mentoring perspective. In fact, their results support the hypotheses that certain activities carried out in developmental networks such as Junior Enterprises influence individual competencies and thereby entrepreneurial intention.

\section{THE ROLE OF CONTEXT IN SHAPING ENTREPRENEURSHIP}

The second part of this book is devoted to the analysis of the influence of context in entrepreneurship. The three chapters included here refer to three very different levels of context. The first of these chapters refers to the closest environment, represented by a venture competition and the members of entrepreneurial teams. Then, the university context is considered in the framework of the construction of entrepreneurial universities. Finally, the influence of a wider cultural context on individuals' perceptions is analysed.

The chapter by Santos, Costa and Caetano focuses on the entrepreneurial potential construct in entrepreneurial teams competing in a venture competition. It assesses the entrepreneurial potential profile of entrepreneurial teams, and uses this evaluation to predict the track finalists and the grand finalist of the venture competition. The study is based on the socio-psychological aspects of entrepreneurial potential profiles and the productivity of each team. The study reflects on the relevance of considering entrepreneurial potential at the team level, considering entrepreneurship in a multilevel perspective. On a more practical note, it stresses that the entrepreneurial potential profile can be a useful tool to point out successful and highly potential teams.

Riviezzo, Napolitano and Garofano, in their chapter, discuss the actual commitment of Italian universities towards their third mission by applying Critical Discourse Analysis. The study is focused on the texts published by the 84 Italian universities on their websites. The methodology employed involves a lexical-statistical study of the texts with the main aim of observing the adopted terminology (vocabulary). Multidimensional statistic techniques are then used to study the discursive practices and reconstruct the major models of sense behaviour. Alongside this, an exploratory study of the social context is carried out to link the texts and the discursive practices to the background conditions. The results seem to suggest the 
new mission of the university does not represent a central theme in the discourse yet, neither in the social context nor within the universities. Moreover, there is some caution in using a rhetoric that celebrates the third mission and there is no evidence of a deliberated appropriation of a commercial vocabulary, as it happened in other different social contexts.

Attention is paid, in Jaén and Liñán's chapter, to the importance of a region's cultural values in determining the entrepreneurial intention of each of its members separately. Based on well-established theory both with respect to cultural values and to entrepreneurial intentions, their study sheds light on the mechanisms through which this influence may take place. Their empirical study is conducted on a large sample of university graduates. Results show that the region's culture indirectly influences the entrepreneurial intention of its members. People in some regions do feel a more positive attitude, subjective norm or perceived behavioural control due to a region's cultural characteristics.

\section{THE ROLE OF INNOVATIVE STRATEGY IN GROWING ENTREPRENEURSHIP}

Part III of the book comprises three chapters that address how strategic choices have a very relevant role to play in the growth of entrepreneurial ventures. Each chapter focuses on one particular aspect. Thus, the first chapter analyses different conceptual approaches to understand the implications of adopting a corporate entrepreneurship strategy. The second chapter focuses on the service business and considers strategic human resource management. The development of absorptive and adaptive capabilities is the central theme in the third chapter.

Grande argues, in his chapter, that engaging in corporate entrepreneurship to increase competitiveness and sustain performance is challenging to most firms, since it often involves new relations with customers, suppliers and contact with less familiar industries. This strategy should yield rewards in the form of a more profitable firm, as has been established in the literature. However, the potential for new value creation and competitive advantages is quite complex. Thus, this conceptual study argues that this potential may be explored through the entrepreneurial orientation (EO), resource based (RBV) and dynamic capability (DC) perspectives. The study links the RBV, EO and DC perspectives respectively to Ricardian, Entrepreneurial and Austrian rents. Each of these perspectives may thus provide their unique insight into how entrepreneurship may create new rent streams and improve performance in firms. Overall, therefore, the study contributes to further 
understanding of how and why corporate entrepreneurship may lead to superior performance in firms.

Rinne's chapter explores the characteristics of the service business and its links with the concept of strategic entrepreneurship (SE). This interpretive analysis is based on existing literature about both the service business and SE, and is supported by qualitative evidence from the managers of small service firms. The findings in this chapter extend the concept of SE by introducing strong links between SE and aspects of the service business and they suggest that specific domains of SE can be linked either to an employee's competence or to managerial skills in the service organization. Based on these findings, a new model for strategic human resource management in small service organizations is introduced.

The chapter by Iakovleva, Oftedal and Foss, in turn, considers the existence of different types of dynamic capabilities. They reflect on the importance of dynamic capabilities in the survival and development of new firms by analysing a multiple case study of three firms. In particular, the chapter focuses on the way that firms featuring emerging technology develop absorptive and adaptive capabilities in their commercialization process. Their results suggest that, for small innovative firms in the early stages of the commercialization process, absorptive capacity may be especially crucial for the development of an innovative product. In turn, adaptive capability seems necessary for a successful commercialization process and firm survival.

\section{INTEGRATING CONTEXT AND STRATEGY IN ENTREPRENEURSHIP}

The chapters in Parts II and III above have stressed the role of both context and strategy in the configuration and progression of firms. The final part integrates both approaches by analysing how the practical implementation of an innovative strategy needs be adapted to the particular setting - or context - in which the firm is placed. The four chapters included in this part range in geographical context from Ghana to Spain and to Norway. They also differ in sectorial context from agro-industry, to cultural and automotive industries, and to the social economy. The strategic choices made in each case provide an increased understanding of how this integration takes place.

The chapter by Vestrum builds upon insights from the social embeddedness and EO approaches to explore how entrepreneurs develop relationships with resource holders in a community to mobilize resources for new community ventures. The findings derive from a longitudinal case 
study of two music festivals in rural communities in Norway. The different personal backgrounds of the entrepreneurs promote different types of resource mobilization strategies: either an incremental resource mobilization strategy building the venture upon existing resources and knowledge within the community, or a more radical strategy by introducing new resources and knowledge to the community. The incremental strategy promotes more embedded relationships between the community venture and the local community, such as closer relationships with a higher level of trust, than the radical resource mobilization strategy. The resource mobilization strategies and the relationships of the venture within the local community are shown to co-evolve and change over time.

The purpose of Taura's chapter is to develop a theoretical and analytic framework within the context of African small and medium enterprise clusters. Drawing from multiple perspectives, the chapter develops a model that clarifies the concept of innovative performances and identifies five measurable dimensions of innovative performances. A set of firms in a leading African automotive cluster in Ghana is analysed. The study finds high variability with regards to a firm's innovative frequency, innovative speed, innovative diffusion and innovative protection. Knowledge driven firms are identified as those investing in knowledge, sharing knowledge and establishing linkages with knowledge-based sources. They are more likely to report 'all rounded' innovative performance. The chapter contributes to the debates on entrepreneurship, innovation and geographical clustering in the context of Africa.

In her chapter, Roaldsen advances the understanding of the business model and entrepreneurial strategies in a mature industry setting. On the basis of a longitudinal case study of two different value chains, the chapter presents a set of propositions that outline (1) how the business model develops from a value chain to a value network configuration, and (2) how the value network configuration enables different types of entrepreneurial strategies. The study suggests the business model is an important concept for firms in mature industries seeking new opportunities for competitive advantage.

The chapter by Guzmán-Alfonso, Barroso-González and GuzmánCuevas devotes attention to the recent increase in importance attached to the social economy. In the case of Spain, public authorities have demonstrated their awareness of the importance of this layer of the economy. Their study attempts to analyse the entrepreneurial quality (entrepreneurial orientation) of the companies that belong to the social economy and to compare them to conventional businesses through a descriptive analysis. Given the high contribution that entrepreneurial ventures make to the economic growth of territories, the study tries to confirm whether 
a business model based on the social economy is a viable and sustainable long-term alternative to conventional businesses. Results show that the social economy model may offer a better alternative than the more prevalent conventional business model in some cases.

Overall, therefore, the chapters included in this book provide an overview of the entrepreneurship field under a process view. They offer relevant insights on how entrepreneurial activity may be developed, shaped and grown. In all three stages, the role of academics and educators is relevant, even though they may be more directly connected to the development stage. Therefore, the insights from these chapters provide justification for the existence of research networks such as ESU itself. At the same time, they also pose relevant new research questions and, thus, open new research perspectives. We can only encourage European researchers to keep on advancing knowledge in the field.

Finally, the time passed since the inception of ESU reflects a significant trajectory. However, it is one which has also left its marks. Professor Joaquín Guzmán-Cuevas, a well-known member of ESU, and co-author of one of the chapters in this book, has recently passed away.

\section{Professor Joaquín Guzmán-Cuevas (Sevilla, 1954-2012)}

Professor Guzmán-Cuevas graduated in Economics and Business from the University of Seville in 1978 and earned his doctorate from the same university in 1986 with the work 'The Financial System and SMEs in Andalusia'. He had been working in a financial institution since 1973, but his university vocation led him, in 1983, to abandon that activity and devote himself thoroughly to teaching and research.

For 29 years, he was a lecturer in Applied Economics at the University of Seville, becoming a full professor in 1997. From 2004 onwards, he also was the head of the department of Applied Economics I. His teaching activities included visiting professorships at other Spanish, European and Latin American universities.

As for his research, it has always been focused primarily on the analysis of the determinants of a region's economic development. Starting with the role of the financial system, he later concentrated on the analysis of the role played by the qualities of enterprises and entrepreneurs. This line of research in entrepreneurship yielded relevant results, which have been published in national and international journals, such as International Small Business Journal, Small Business Economics and Entrepreneurship and Regional Development. However, a less well-known line of research in Professor Guzmán-Cuevas's work, perhaps due to its philosophical character, has been the analysis of the role of ethics in the development of economic science. This field of research led him to reconsider the values on which the capitalist growth model is based. In the later years of his career, this resulted in a greater interest in social entrepreneurship. 
His contribution to the ESU network has been enthusiastic ever since he joined back in 2006. Every person having had the opportunity to meet him could say he was a most joyful and supportive colleague, and a researcher passionate about entrepreneurship. May these words serve as a modest tribute to Joaquín.

\section{REFERENCES}

Ajzen, I. (2006), 'Constructing a TPB questionnaire: conceptual and methodological considerations'. Available from http://people.umass.edu/aizen/pdf/tpb. measurement.pdf (accessed April 2014).

Borch, O.J., A. Fayolle, P. Kyrö and E. Ljunggren (2011), Entrepreneurship Research in Europe: Evolving Concepts and Processes, European Research in Entrepreneurship series, Cheltenham, UK and Northampton, MA, USA: Edward Elgar.

Fayolle, A. and P. Kyrö (2008), The Dynamics between Entrepreneurship, Environment and Education, European Research in Entrepreneurship series, Cheltenham, UK and Northampton, MA, USA: Edward Elgar.

Fayolle, A., P. Kyrö, T. Mets and U. Venesaar (2013), Conceptual Richness and Methodological Diversity in Entrepreneurship Research, European Research in Entrepreneurship series, Cheltenham, UK and Northampton, MA, USA: Edward Elgar.

Fayolle, A., P. Kyrö and J.M. Ulijn (2005), Entrepreneurship Research in Europe: Outcomes and Perspectives, Cheltenham, UK and Northampton, MA, USA: Edward Elgar.

Fayolle, A. and K. Todorov (2011), European Entrepreneurship in the Globalizing Economy, European Research in Entrepreneurship series, Cheltenham, UK and Northampton, MA, USA: Edward Elgar. 